\title{
SITES CONSTRUÍDOS POR ADOLESCENTES: NOVOS ESPAÇOS DE LEITURA/ESCRITA E SUBJETIVAÇÃO
}

\author{
Maria Teresa de Assunção Freitas
}

\begin{abstract}
RESUMO: $\mathrm{O}$ artigo relata uma pesquisa qualitativa de abordagem sócio-histórica, que teve como objetivo a compreensão de sites construídos por adolescentes, como espaços de leitura/escrita e de subjetivação. A leitura/escrita hipertextual se dinamiza e flexibiliza na e pela linguagem, que trava um diálogo com outras interfaces semióticas, o que origina diversificadas formas de textualidade e gêneros discursivos. A partir da categoria do dialogismo bakhtiniano, compreendemos como o hipertexto digital favorece o diálogo entre textos e entre pessoas. Os adolescentes transitam pelo espaço cibernético, reelaborando vivências próprias de seu cotidiano a partir das práticas discursivas que ali produzem. Discutimos, portanto, como os sites construídos por adolescentes podem estar propiciando, por meio da leitura/escrita digital, novas formas de interação e novas possibilidades para a constituição da sua subjetividade.
\end{abstract}

Palavras-chave: Leitura/escrita. Sites. Adolescentes. Subjetivação.

\section{Sites CONSTRUCTED BY TEENAGERS: \\ NEW SPACES FOR READING/WRITING AND SUBJECTIVITY}

ABSTRACT: The article mentions a qualitative research on sociohistorical approach, which has the objective the understanding of sites constructed by teenagers, as spaces for reading/writing and subjectivity. The hyper textual reading/writing becomes dynamic and flexible in and through the language, that links a dialogue with other semiotic interfaces, what originates diversified forms of textuality and discursive genders. As of the Bakhtin's dialogism category, we understand how the digital hypertext favors the dialogue

\footnotetext{
* Doutora em educação pela Pontifícia Universidade Católica do Rio de Janeiro (PUC-RIO) e professora da Faculdade de Educação da Universidade Federal de Juiz de Fora (UFJF). E-mail: mtl@acessa.com
} 
among texts and among people. Teenagers pass through the cyber space, re-elaborating their own existence of their daily lives starting from discursive practices produced there. We discuss however, how the sites constructed by teenagers can be propitiating through digital reading/writing, new ways of interaction and new possibilities for the constitution of their subjectivity.

Key words: Reading/writing. Sites. Teenagers. Subjectivity.

\section{O objeto de estudo e os caminhos metodológicos}

A presentamos neste texto o relato de uma pesquisa que buscou compreender a leitura/escrita de adolescentes na internet. ${ }^{1}$ Investigamos, numa pesquisa anterior, ${ }^{2}$ as práticas discursivas de adolescentes em chats e e-mails de listas de discussão sobre seriados televisivos. Desejando aprofundar algumas questões levantadas, continuamos essa investigação voltando nosso foco para os sites construídos por adolescentes. Procuramos compreendê-los como espaços de produção de leitura/escrita e de subjetivação.

Trabalhamos com uma pesquisa qualitativa de abordagem sóciohistórica, ${ }^{3}$ desenvolvendo esforços para a construção de estratégias metodológicas coerentes com o enfoque teórico adotado e com o objeto de estudo. Iniciamos a pesquisa com um exercício preliminar de navegação pela internet com o qual listamos 72 sites. A partir desse exercício percebemos a distinção entre os sites construídos por e para adolescentes. Listados e visitados esses sites, com uma rápida leitura, discutimos sobre a difícil tarefa a que nos dispusemos. Como penetrar neles, como apreender a leitura/escrita ali presente? Percebemos que poderíamos iniciar um processo de compreensão procurando em um Estudo Piloto, e fazendo uma leitura mais aprofundada de apenas dois sites, escolhidos aleatoriamente em nossa listagem: <http//dama_da_lua.vilabol.uol.com.br> (criado por adolescente) e <http//mundoadolescente.matrix.com.br $>$ (criado para adolescentes). Consideramos que esse Estudo Piloto possibilitaria a construção de critérios que indicassem os rumos metodológicos da investigação propriamente dita. Fizemos uma primeira caracterização de cada site a partir dos dois endereços anteriormente indicados. $\mathrm{O}$ site produzido para adolescentes assemelhava-se muito às revistas impressas destinadas a este público. A HP (home page ou página de entrada) possuía características de um índice de revista impressa, com os 
links convidando à navegação pelas diferentes sessões dessa revista on-line. $\mathrm{Na}$ HP apresentavam-se muitos slogans para chamar a atenção, propagandas comerciais, um discreto apelo ao consumo, além de uma categorização padronizada dos interesses adolescentes: sexo, drogas, beleza, saúde, moda, filmes, televisão, jogos, entre outros. Foi difícil entrar em contato com os autores, pois estes não estavam definidos, aparecendo sob o nome de uma "empresa" produtora do site. Na maior parte dos contatos por e-mail não obtivemos respostas. Em contrapartida, ao caracterizarmos a página construída por uma adolescente de 18 anos, notamos que esse site girava em torno da autora e de seus interesses: amigos, família, namorado, turma da escola, dicas de beleza para pessoas com suas características físicas, espaço para contato, troca de mensagens, fotos das pessoas mais próximas, crenças religiosas, entre outros. Enfim, havia uma marca de autoria e uma escrita mais subjetiva. Na verdade, a adolescente manifestava interesse em interagir com pessoas e supunha um auditório social para o qual construía seu site. Prontamente respondia nossos e-mails e esses contatos foram uma oportunidade de conhecêla melhor e ao seu trabalho relacionado à construção do site.

Terminamos o Estudo Piloto com uma nova orientação para o trabalho de campo. Em primeiro lugar, optamos por trabalhar apenas com sites construídos por adolescentes por estes se mostrarem mais adequados aos objetivos propostos. Retornamos então, à nossa listagem inicial (endereços dos sites) escolhendo seis sites que se constituíram em nosso material de estudo: <www.malhacaome.hpg.com.br>, <www.justlia.net>, $<w w w . s w e e t l i a . j u s t l i a . n e t>$, <www.palace.justlia.net>, <www.arrobairc.cjb.net>, $<$ www.rampagesite.hpg.ig.com.br $>$.

Planejamos o processo de análise desses sites compreendendo que sua leitura poderia ser considerada uma observação. $\mathrm{Na}$ abordagem sócio-histórica de pesquisa, o que se busca com a observação é uma compreensão ativa, que no dizer de Bakhtin (1988) é responsiva, construída no encontro dos diferentes enunciados produzidos entre os sujeitos. "Mais do que participante, esta observação é caracterizada pela dimensão alteritária: o pesquisador ao participar do evento observado constitui-se parte dele, mas ao mesmo tempo mantém uma posição exotópica que lhe possibilita o encontro com o outro" (Freitas, 2003b, p. 32). O que se apresenta como inacessível a um sujeito é o que preenche o olhar de um outro. Dessa forma, compreendemos que, ao situarmo-nos diante dos sites, o excedente de nossa visão é que nos possibilitaria dar uma certa completude (sempre in- 
Sites construídos por adolescentes: novos espaços de leitura/escrita e subjetivação

completa) ao que estaríamos focalizando. Portanto, essa posição exotópica foi por nós considerada tão importante quanto o material que se apresentava exposto no site presente na tela do computador. Assim, no processo de compreensão dos sites, orientados por esta perspectiva teóricometodológica, buscamos construir com os sujeitos os sentidos dos eventos observados. Construímos um trabalho interativo, no movimento de leitura da HP, focalizando um de seus links, ou navegando num trajeto próprio por entre diversos links, tendo sempre a oportunidade de contato via e-mail, via link: "fale conosco", ou pelo "livro de recados", para interagir com o/os autor/es de materiais presentes nos sites. Após cada sessão de navegação, o pesquisador-observador registrava o que havia observado e compreendido numa nota de campo.

Completando esse trabalho investigativo definimos, com o apoio do referencial teórico adotado, as seguintes categorias: a) a leitura/escrita hipertextual nos sites de adolescentes e a constituição de sua subjetividade; b) dialogismo e intertexto nos sites de adolescentes; c) os gêneros discursivos com relação à leitura/escrita na internet. Procuramos, assim, construir sentidos que nos levassem a uma compreensão dos dados coletados como uma resposta às questôes orientadoras formuladas.

Os sites de adolescentes como espaços de leitura/escrita hipertextual e de construção da subjetividade

Este trabalho nos permitiu conhecer e construir uma visão ampla da leitura e da escrita como instrumentos culturais e processuais que se fazem no e pelo aparato técnico da internet, e, mais especificamente, compreender os sites construidos/produzidos por adolescentes como um espaço de produção de leituralescrita.

A construção hipertextual dos sites, que se assemelha a um jogo desafiador para o adolescente, leva o seu construtor a diferentes práticas de leitura/escrita. Essas vão desde uma leitura técnica e informacional sobre as operações necessárias para organização da estrutura da HP e sua dinâmica, com atividades de escrita a acionar diversos comandos, até atividades de leitura/escrita que compõem o conteúdo do site alimentando seus diversos links. Para a construção de um site, o adolescente precisa de conhecimento dos códigos de informática e de sua leitura. Este aprendizado se dá no cotidiano, pela interação entre adolescentes e outros internautas. 
$\mathrm{O}$ adolescente, ao produzir um site, busca informações sobre sua construção por meio de listas de discussôes, chats e outros sites da web. Dessa forma, a construção de sites é sempre coletiva. Além disso, nesse processo doméstico, a construção dá-se pelo mecanismo "copiar e colar", ou seja, geralmente o adolescente copia o código-fonte e cola os efeitos de outros sites, o mesmo ocorrendo com o próprio conteúdo dos textos em razão da facilidade de acesso e da rapidez. Este processo faz de seus autores ao mesmo tempo leitores, produtores e emissores de informaçōes. Uma outra questão relacionada à construção/produção de sites por adolescentes está no apagamento progressivo da autoria pessoal para uma coletiva, durante a sua construção. Ocorre que, interagindo com outros adolescentes em busca das regras do jogo e de mecanismos para ganhá-lo (conseguir produzir a HP e seu respectivo site), uma das primeiras regras descobertas é a de que se pode utilizar tudo o que está disponível no mundo virtual (figuras, textos de outros sites etc.), da maneira e da forma que se quer ou se acha necessário. Cabe-nos indagar como ficam as relações de apropriação de textos e obras, a partir da situação possibilitada pela produção dos sites.

Realizam-se também práticas de leitura/escrita que se reportam a outros suportes como livros, revistas, jornais e aquelas possibilitadas pela navegação pelo próprio hipertexto eletrônico. Uma vez construídos, os sites apresentam-se como espaços nos quais adolescentes transitam lendo/escrevendo sobre sua própria pessoa (como nos blogs, diários virtuais onde se expõem para que leitores penetrem nessa intimidade mostrada), sobre unidades temáticas relacionadas a objetos de interesse comum (uma banda musical, um grupo que se reúne em algum chat, um seriado televisivo etc.) e sobre interesses diversos característicos de sua fase de desenvolvimento ou propostos pela mídia. Toda essa leitura/escrita é enraizada na vida, interativa, dirigida a interlocutores reais. Escrevem para serem lidos e por um auditório social específico: seus coetâneos adolescentes. Essa leitura, por sua vez, em seu percurso hipertextual, converte-se em escrita nas intervençôes feitas nos textos, nos contatos estabelecidos nos livros de recados ou nos e-mails. Escrita que se inscreve no já-escrito e o reescreve levando a uma autoria coletiva. Leitura/escrita que se constitui num diálogo constante com os textos presentes nos diferentes links e com pessoas, permitindo uma interlocução na qual outros eus vão constituindo o eu do adolescente.

Ao aprofundar a análise do hipertexto virtual como um local de produção de leitura/escrita, vislumbramos os sites construídos/produzi- 
Sites construídos por adolescentes: novos espaços de leitura/escrita e subjetivação

dos por adolescentes como um espaço de construção da subjetividade. Estando o texto informatizado exigindo um leitor/escritor que possua conhecimentos acerca de como se inserir nas páginas virtuais, ele acaba possibilitando uma atividade leitora que, por meio da interpretação, traz em si uma forma de criação pessoal, que pressupõe uma linguagem própria, estratégias diversas e possibilidades outras que transformam os contextos em que se escreve, e o que se escreve. Modifica-se, assim, a natureza dessa escrita/leitura, marcada pela interatividade que se faz presente de forma especial no contexto virtual. Há mesmo, no dizer de Aranha Filho (2003), uma espécie de vocação das redes para formar comunidades, para criar laços sociais entre seus usuários. Entretanto, é preciso compreender a especificidade dessas interações sociais possibilitadas pela internet. Não se trata de interaçóes face a face, mas de um encontro virtual com o outro mediado pela leitura/escrita. É assim que Bretas (2001) entende que a tecnologia das redes virtuais pode configurar "novos espaços de sociabilidade, inaugurando novas práticas de estar com o outro, e, inclusive, propiciando uma aproximação local” (p. 39). De acordo com Lévy (1996), embora o real não se oponha ao virtual, é preciso estarmos atentos às diferenças e semelhanças entre o mundo concreto e o mundo virtual. Neste sentido, ao passo que as interações sociais na realidade física se realizam de forma presencial, face a face, no mundo virtual elas são de natureza puramente simbólica. Mas, como salienta Turkle (1997), apesar dessa natureza simbólica, as interaçóes mediadas pela internet são ações humanas como as interações presenciais. Completamos essas reflexões dizendo que as interaçôes via internet são possibilitadas por uma produção de linguagem que, por intermédio da leitura/escrita em tela, permite um encontro virtual mas também real de pessoas. Em nossa pesquisa percebemos que o adolescente-internauta amplia suas interações lendo/escrevendo seja em chats, e-mails ou sites. O site concentra de uma maneira especial estas interações, formando verdadeiras comunidades virtuais. Compreendemos, assim, que os sites podem estar propiciando aos adolescentes contemporâneos um espaço interativo que contribui para a constituição de sua subjetividade. Encontramos apoio para dizer isto em Vygotsly e Bakhtin, os quais consideram que a consciência é engendrada no social, a partir das relações que os homens estabelecem entre si, pela mediação da linguagem. Para Bakhtin (1988) o psiquismo situa-se num entrelugar: entre o organismo e o mundo exterior, e a forma de mediar a relação entre os dois materializa-se nos signos, na linguagem. Para esse autor 
a consciência individual adquire forma e existência nos signos criados por um grupo organizado no curso de suas relaçôes sociais. Os signos são o alimento da consciência individual, a matéria de seu desenvolvimento, e ela reflete sua lógica e suas leis. A lógica da consciência é a lógica da comunicação ideológica da interação semiótica de um grupo social. (Bakhtin, 1988, p. 35-36)

Continuando sua exposição, Bakhtin afirma que a palavra é o primeiro meio da consciência individual, sendo o material semiótico do discurso interior. Entretanto, essa consciência individual para ele é sempre social, pois o eu forma-se na interação com outros eus.

Vygotsky (1996, 1991), ao afirmar que a consciência é um contato social consigo mesmo, também participa da idéia de que a consciência individual se forma a partir do social. Esse autor concebe que o sujeito se constitui na relação com os outros, sendo o meio social formador da subjetividade. Para que algo se torne intrapessoal, necessariamente deve passar pelo meio, pelas relações interpessoais.

Vygostky e Bakhtin entendem o homem como sujeito da e na História, concebendo a cultura como o meio de existência por intermédio do qual se constitui a natureza humana (Freitas, 1997). Seguindo esta linha de pensamento, é imprescindível que consideremos as transformaçôes culturais e os novos conhecimentos resultantes da rápida produção e circulação de informações, principalmente a partir do desenvolvimento do computador e da internet. Neste sentido, compreendemos a internet como criadora de uma nova sensibilidade cultural e social, propiciadora de outras formas de interação e intersubjetividades. Turkle (1997) vê os computadores como instrumentos que não só fazem coisas para nós, mas que fazem coisas conosco, influindo em nossos modos de pensar sobre nós mesmos e sobre outras pessoas. É neste sentido que a autora percebe a dialética do homem que ao interferir na natureza transformando-a também se transforma. "Construímos nossas tecnologias e nossas tecnologias nos constroem a nós mesmos em nossos tempos. Nossos tempos nos fazem, nós mesmos fazemos nossas máquinas, nossas máquinas fazem nossos tempos" (Turkle, 1997, p. 60-61). ${ }^{4}$ A autora vê as telas dos computadores como os lugares nos quais projetamos muito de nós mesmos, nossas vivências pessoais, fantasias, desejos etc. Em nossa pesquisa, percebemos que, principalmente para os adolescentes, o espaço virtual apresenta-se integrado ao seu dia-a-dia, sendo parte de sua realidade, local de encontro com outras pessoas e com os interesses própri- 
Sites construídos por adolescentes: novos espaços de leitura/escrita e subjetivação

os da idade de transição. Eles transitam pelo espaço cibernético, explorando a web num movimento de acessar uma coisa, depois outra, fazer conexões, juntar elementos diferentes, realizando um verdadeiro exercício de bricolage. E nesse movimento vão reelaborando vivências próprias de seu cotidiano a partir das práticas discursivas que ali produzem. Isso se evidencia nos diferentes links e principalmente nos blogs, os diários on-line nos quais se projetam na tela e expõem sua privacidade para atrair a atenção de outros internautas ou buscar sua identidade numa interação com a própria língua, ou procurar a compreensão de si mesmos pelo exercício da escrita na qual se revelam.

\section{O hipertexto digital como um evento textual dialógico}

Focalizamos o processo de leitura/escrita presente nos sites construídos por adolescentes como uma atividade que traz em si o dialogismo bakhtiniano, já que estamos diante do hipertexto digital que favorece uma construção dialogada ou mesmo de muitas vozes.

O hipertexto, de acordo com Marcuschi (1999), possibilita novas formas de ler e escrever que se caracterizam por um estilo não-linear e associativo, em que a noção de texto primeiro, segundo, original e referência cai por terra. As informações textuais são combinadas com imagens (animadas ou fixas) e sons, organizadas de forma que se permita uma leitura (ou navegação) não-linear, baseada em indexações e associaçôes de idéias e conceitos, sob a forma de links. Estes, entendidos como ligações, são marcas que conectam um nó com outro e agem como portas virtuais que abrem caminhos para outras informações. Os links são geralmente representados por pontos na tela, palavras ou frases em destaque (negrito, itálico ou em cores), mas também podem ser gráficos ou ícones, que indicam a origem ou o destino das ligaçôes. Estas levam o leitor/escritor para um novo tópico, mostram uma referência, fornecem informações adicionais, exibem uma ilustração, foto, um esquema, executam um programa de computador, indicam outro(s) site(s). Para Lévy (1999), o hipertexto é um conjunto de nós ligados por conexões. Os itens não estão ligados linerarmente, como em uma corda cheia de nós, mas cada um deles, ou a maioria, estende suas conexôes em estrela, de modo reticular.

O navegador, no seu processo de leitura/escrita por meio dos links do hipertexto, segue uma trilha que é uma seqüência de nós ligados re- 
presentando a rota seguida por ele. Navegar em um hipertexto significa desenhar um percurso em uma rede que pode ser tão complicada quanto possível. Porque cada nó pode, por sua vez, conter uma rede interativa. Portanto, pode-se dizer que navegar significa direcionar uma mudança de foco ou movimentação com relação ao conhecimento disponível na base de uma HP. Assim, o escritor de um hipertexto produz uma série de previsões para ligações possíveis entre segmentos, que se tornam opções de escolha para os hipernavegadores. $\mathrm{O}$ interessante é que cada leitor faz suas escolhas, realiza interferências e percorre seus caminhos que, no geral, não são similares ao de outro leitor. E nesses caminhos vai encontrando diferentes textos que se interconectam e se interpenetram. Essa leitura pode até levar a intervenções de escrita que podemos considerar uma escrita colaborativa ou dialogada. Nesse espaço de navegação é como se estivéssemos imersos num continuum de discursos espalhados por imensas redes digitais que dialogam entre si.

É interessante lembrar que o termo "hipertexto" foi cunhado por Theodor Holm Nelson em 1964, para se referir a uma escritura eletrônica não-seqüencial e não-linear, que se bifurca e permite ao leitor o acesso a um número praticamente ilimitado de outros textos a partir de escolhas locais e sucessivas, em tempo real. Escolhas voláteis tão passageiras quanto as conexões estabelecidas por seus leitores. Assim, o leitor tem condições de definir interativamente o fluxo de sua leitura, a partir de assuntos tratados no texto, sem se prender a uma seqüência fixa ou a tópicos estabelecidos por um autor. Trata-se de uma forma de estruturação textual que faz do leitor simultaneamente co-autor do texto final. O hipertexto digital possibilita, pois, um processo de escritura/leitura eletrônica multilinearizado, multisseqüencial e indeterminado, configurando-se como um espaço propício ao diálogo entre textos e interlocutores. Bolter, citado por Marcuschi (1999), fornecenos argumentos para tal ao afirmar que o hipertexto é um texto interativo, pois, em razão de sua multissemiose e acessibilidade ilimitada e pela contínua relação de um leitor-navegador com múltiplos autores em quase sobreposição em tempo real, chega a simular uma interação verbal face a face. Também Snyder (1997), citado por Marcuschi (1999), lembra este aspecto de diálogo entre textos e pessoas quando diz que o hipertexto obscurece os limites entre leitores e escritores já que é construído parcialmente pelos escritores que criam as ligaçóes, e parcialmente pelos leitores que decidem os caminhos a 
seguir. Na realidade, com o hipertexto, tem-se a impressão de uma autoria coletiva ou de uma espécie de co-autoria. A leitura torna-se simultaneamente uma escritura, já que o autor não controla mais o fluxo da informação. O leitor determina não só a ordem da leitura, mas o conteúdo a ser lido. Embora o leitor do hipertexto não escreva o texto no sentido tradicional do termo, ele determina o formato da versão final de seu texto, que pode ser muito diversa daquela proposta pelo autor. Ao se mover livremente, navegando por uma rede de textos, o leitor procede a um descentramento do autor, fazendo, de seus interesses de navegador, o fio organizador das escolhas e das ligações (Marcuschi, 1999).

Nessa visão, o hipertexto pode ser visto como um evento textualdialógico. "Cada ponto é um nó de onde se pode partir para cumprir a navegação da rede textual onde o texto é evento - ato dialógico por excelência" (Machado, 1996, p. 262). Ato dialógico este que se dá em duas vias: diálogo entre textos e o diálogo entre pessoas. Contudo, essas duas vias estão diretamente interconectadas, tornando impossível vislumbrar uma sem considerar a outra. Podemos dizer que cada link de um site se apresenta como um indicador de uma enunciação, gerando assim uma corrente de comunicação verbal ininterrupta que une interesses e experiências partilhadas em processos de comunicação, interpretação e negociação, possibilitando que as pessoas construam de forma partilhada seus conhecimentos. O hipertexto pode promover a construção social do conhecimento pela interação que redistribui o poder e a autoridade na produção textual.

\section{Os gêneros discursivos no ciberespaço}

A questão dos gêneros discursivos que emergem no contexto ciberespacial foi também discutida na análise dos achados da pesquisa. Segundo Bakhtin (1988), a linguagem só pode ser analisada, na sua devida complexidade, quando considerada um fenômeno sócio-ideológico e apreendida dialogicamente no fluxo da História, ou seja, só pode ser analisada em seu vínculo com a vida e a História. Ainda no dizer do autor (1992), a utilização da língua efetua-se em forma de enunciados orais e escritos que emergem de diferentes esferas da atividade humana. Cada esfera de utilização da língua "elabora seus tipos relativamente estáveis de enunciados” (Bakhtin, 1992, p. 280), que são os gêneros do discurso. Ao compreender a enunciação como unidade da 
comunicação verbal, partimos do pressuposto de que ela se constrói no processo constituído por uma interação verbal específica, nascida de um tipo de intercâmbio comunicativo social também específico.

Perpassando a discussão acerca dos gêneros do discurso, trazida pela Teoria Enunciativa da Linguagem de Mikhail Bakhtin, discutimos a possibilidade de nascimento de novos gêneros a partir do aparato técnico da internet, compreendendo os sites como portadores de espécies diversificadas de gêneros, inseridos numa esfera discursiva mais ampla. Os gêneros discursivos, segundo Bakhtin (1992), são compostos indissoluvelmente por três elementos: conteúdo temático, estilo e construção composicional. São "tipos estáveis" que permitem a interlocução, porém não se encerram numa "tipologização", podendo, antes, constituírem uma combinação, uma relação com outros gêneros. Os gêneros secundários, portanto, são resultantes de uma espécie de transformação dos primários. É a fusão de dois que resulta num outro. O gênero discursivo, para Bakhtin, acompanha a variabilidade dos usos que se fazem da língua num determinado tempo. Cada época gera seus próprios gêneros discursivos. Machado (1997) comenta que, para Bakhtin, o gênero vive do presente, mas recorda seu passado, seu começo. Sua vida é marcada pela capacidade de renovar-se em cada época. Os gêneros criam verdadeiras cadeias que, por se reportarem à grande temporalidade, acompanham a variabilidade de usos da língua num determinado tempo. Neste sentido, a autora compreende que o gênero não pode ser pensado fora do cronotopo. Vivemos hoje um momento cultural em que "oralidade, escritura impressa e escritura eletrônica não são estágios distintos, mas uma conjugação. E é desse lugar que as idéias de Bakhtin sobre o texto e os gêneros assumem uma outra configuração, vivem o seu renascimento" (Machado, 1996, p. 254). O que pudemos depreender dos achados dessa pesquisa é que os textos se dão de várias formas, interagem, em decorrência do uso que se faz da língua. Poderíamos dizer que os textos se materializam no e por meio dos gêneros. São os gêneros, portanto, dinamizadores de textos. É a alteração na estrutura composicional que produz textos diferentes no interior de um mesmo gênero. Hoje, com a tecnologia informática, a escrita exige novas operações em razão de novas necessidades, como a própria velocidade dos bits, que estão levando a novas formas de escrever com um retorno ao gênero primário, com transformações. Temos um gênero que talvez possamos chamar de internético, com uma variada tipologização de textos. Uma variabilidade que se dá 
Sites construídos por adolescentes: novos espaços de leitura/escrita e subjetivação

pela interlocução de uma nova característica na composição do gênero do discurso. Os gêneros coexistem e são constitutivos uns dos outros. Todo "novo gênero" perpetua a sua existência com os novos gêneros que lhe deram origem (Bernardes et al., 2003).

\section{Reflexões finais}

Refletindo sobre a pesquisa realizada, pudemos assumir que a perspectiva sócio-histórica, e nela, de um modo especial, a Teoria Enunciativa de Mikhail Bakhtin, pode ser um ponto de partida importante para compreendermos a leitura/escrita no novo suporte digital. Embora Bakhtin tenha escrito seus textos numa época na qual a internet era algo ainda impensável, seus conceitos podem ser adaptados para direcionarem nosso olhar a essa realidade. Segundo Machado (1996), as dimensões do sistema teórico de Bakhtin parecem avançar cada vez mais para fora de seus limites, fornecendo instrumentos para se pensar questôes específicas da linguagem, do pensamento, dos sistemas de signos tais como são vivenciados hoje em nossa cultura. A partir desse comentário a autora indaga:

Como se comportam seus conceitos quando ambientados no conjunto da cultura em que o texto impresso convive com o texto eletrônico? É possível estender a teoria do dialogismo para a compreensão dos produtos escritos em espaços textuais constituídos pelos recursos típicos dos ambientes da tecnologia eletrônico-digital, jamais imaginados por Bakhtin? (Machado, 1996, p. 232)

Reconhecendo que Bakhtin não experienciou essa realidade atual em que as tecnologias digitais e a rede mundial de computadores geram novas formas de comunicação e textualidades, podemos, no entanto, pensar que o olhar extraposto a partir do qual via a linguagem lhe permitiu valorizar o discurso múltiplo, dialógico, a compreensão de que todo discurso recolhe o discurso alheio. Esses aspectos por ele valorizados estão presentes na linguagem que se produz no meio digital. No contexto específico da esfera digital da comunicação, as categorias bakhtinianas podem ajudar numa compreensão de suas peculiaridades. Perde o homem, no ciberespaço, quaisquer indícios da materialidade, preservando, no entanto, toda riqueza e complexidade das múltiplas formas de expressão da linguagem. É nesse ponto que se pode insistir nos pres- 
supostos deste autor como um terreno extremamente fértil para a concretização de uma reflexão. Ora, para Bakhtin (1993) a língua não é algo imóvel, morto ou petrificado da vida social, mas move-se continuamente e seu desenvolvimento segue a vida social. Nas vicissitudes das palavras encontram-se as vicissitudes da sociedade dos seus usuários. Esse movimento progressivo da língua se realiza no processo de relação homem/homem, uma relação não só produtiva mas verbal. Nessa comunicação se elaboram os mais diversos tipos de enunciações que se adequam às situações nas quais se realizam. Para compreender as enunciações é preciso ver o vínculo com a situação social que as provoca. Por tudo isso, ao focalizarmos os sites construídos por adolescentes na internet, Bakhtin constituiu-se em nosso interlocutor e com ele compreendemos que o ciberespaço emerge como um novo espaço de interaçóes, possibilitando a estes internautas uma leitura/escrita não-seqüencial, não-linear, que se ramifica permitindo o acesso praticamente ilimitado de uma variada tipologização de textos pertencentes ao gênero internético, a partir de escolhas locais e sucessivas, em tempo real.

De todo o trabalho desenvolvido, consideramos, enfim, importante assinalar que pesquisas nas ciências humanas, em especial no campo da educação e da linguagem, como nessa investigação, permitem a compreensão de que a tecnologia pode ser pensada como mediadora da construção do conhecimento e de transformações da subjetividade.

Recebido em fevereiro de 2005 e aprovado em março de 2005.

\section{Notas}

1. Trata-se da pesquisa "A construção/produção da leitura/escrita de adolescentes na internet e na escola: uma abordagem sociocultural (continuidades e desdobramentos)", apoiada pelo CNPq e pela FAPEMIG e desenvolvida de 2001 a 2003 pelo grupo de pesquisa Linguagem, Interação e Conhecimento (LIC), da Faculdade de Educação da UfJF, coordenado pela Prof. ${ }^{a}$ Dr. ${ }^{a}$ Maria Teresa de Assunção Freitas.

2. Trata-se da pesquisa "A construção/produção da escrita de adolescentes na internet e na escola: uma abordagem sociocultural", apoiada pelo CNPq e pela FAPEMIG e desenvolvida de 1999 a 2001 pelo grupo de pesquisa Linguagem, Interação e Conhecimento (LIC), da Faculdade de Educação da UfJf, coordenado pela Prof. ${ }^{a}$ Dr. ${ }^{a}$ Maria Teresa de Assunção Freitas, tendo como vice-coordenador o prof. Dr. Sérgio Roberto Costa.

3. Ver mais sobre essa questão em Freitas (2002).

4. Tradução livre do espanhol.

Cad. Cedes, Campinas, vol. 25, n. 65, p. 87-101, jan./abr. 2005

Disponível em <http://www.cedes.unicamp.br> 
Sites construídos por adolescentes: novos espaços de leitura/escrita e subjetivação

\section{Referências bibliográficas}

ARANHA FILHO, J. Tribos eletrônicas: usos e costumes. Disponível em: <http://www.Alternex.com.br/ esocius/t-jaymehtml>. Acesso em: 14 jun. 2003.

BAKTHIN, M.M. (Volochínov). Marxismo e filosofia da linguagem. São Paulo: Hucitec, 1988.

BAKTHIN, M.M. Os gêneros do discurso. In: BAKTHIn, M.M. Estética da criação verbal. São Paulo: Martins Fontes, 1992. p. 277-326.

BAKTHIN, M.M. La construcción de la enunciación. In: Silvestri, A.; BLANCK, G. Bajtín y Vigotski: la organizacion semiótica de la conciencia. Barcelona: Anthropos, 1993. p. 245-277.

BERNARDES, A.S. et al. Por uma nova concepção de gênero discursivo: a perspectiva bakhtiniana e o contexto da internet. In: FreITAS, M.T.A. $A$ construção/produção da escrita na internet na escola: uma abordagem sociocultural (continuidades e desdobramentos). 2003. (Relatório de pesquisa CNPq)

BRETAS, M.B.A. Elementos metodológicos para a abordagem das interações telemáticas. In: FAusto NetO, A. et al. (Org.). Interação e sentidos no ciberespaço e na sociedade. Porto Alegre: EDIPUCRS, 2001. p. 29-48.

FREITAS, M.T.A. Nos textos de Vygotsky e Bakhtin: um encontro possível. In: BraIT, B. (Org.). Bakhtin, dialogismo e construção do sentido. Campinas: Editora da UnICAMP, 1997. p. 311-330.

FREITAS, M.T.A. A abordagem sócio-histórica como orientadora da pesquisa qualitativa. Cadernos de Pesquisa, São Paulo, n. 116, p. 21-39, jul. 2002 .

FREITAS, M.T.A. A construção/produção da escrita na internet na escola: uma abordagem sociocultural (continuidades e desdobramentos). 2003. (Relatório de pesquisa CNPq)

FREITAS, M.T.A. A perspectiva sócio-histórica: uma visão humana da construção do conhecimento. In: Freitas, M.T.A.; Kramer, S.; Jobim E SouzA, S. (Org.). Ciências humanas e pesquisa: leituras de Mikhail Bakhtin. São Paulo: Cortez, 2003b. 
LÉVY, P. O que é o virtual? 2. ed. Rio de Janeiro: Editora 34, 1996. LÉVY, P. Cibercultura. 1. ed. Rio de Janeiro: Editora 34, 1999.

MACHADO, I. Os gêneros e a ciência dialógica do texto. In: FARACO, C.A. et al. (Org.). Diálogos com Bakhtin. Curitiba: UfPr, 1996. p. 225272.

MACHADO, I. Os gêneros e o corpo do acabamento estético. In: BRAIT, B. (Org.). Bakhtin, dialogismo e construção do sentido. Campinas: UNICAMP, 1997. p. 141-158.

MARCUSCHI, L.A. O hipertexto como um novo espaço de escrita em sala de aula. Trabalho apresentado no 4. Forum de Estudos Lingüísticos. Rio de Janeiro, 1999.

TURKLE, S. La vida em la pantalla. 1. ed. Barcelona: Ediciones Paidós Ibérica, 1997.

VIGOTSKI, L.S. A consciência como problema da psicologia do comportamento. In: VIGOTSKI, L.S. Teoria e método em psicologia. São Paulo: Martins Fontes, 1996. p. 55-86.

VIGOTSKI, L.S. A formação social da mente. 4. ed. São Paulo: Martins Fontes, 1991. 